\title{
Managed Mental Health Care: An Oxymoron of Ethics?
}

Jonathan M. Metzl M.D.

Follow this and additional works at: https://jdc.jefferson.edu/jeffjpsychiatry

Part of the Psychiatry Commons

Let us know how access to this document benefits you

\section{Recommended Citation}

Metzl, Jonathan M. M.D. (1996) "Managed Mental Health Care: An Oxymoron of Ethics?," Jefferson Journal of Psychiatry. Vol. 13 : Iss. 1 , Article 6.

DOI: https://doi.org/10.29046/JJP.013.1.005

Available at: https://jdc.jefferson.edu/jeffjpsychiatry/vol13/iss1/6

This Article is brought to you for free and open access by the Jefferson Digital Commons. The Jefferson Digital Commons is a service of Thomas Jefferson University's Center for Teaching and Learning (CTL). The Commons is a showcase for Jefferson books and journals, peer-reviewed scholarly publications, unique historical collections from the University archives, and teaching tools. The Jefferson Digital Commons allows researchers and interested readers anywhere in the world to learn about and keep up to date with Jefferson scholarship. This article has been accepted for inclusion in Jefferson Journal of Psychiatry by an authorized administrator of the Jefferson Digital Commons. For more information, please contact: JeffersonDigitalCommons@jefferson.edu. 


\title{
Managed Mental Health Care: An Oxymoron of Ethics?
}

\author{
Jonathan M. Metzl, M.D.
}

I have spent the past three and a half years working as a resident in psychiatry at Stanford University Hospital. Over the course of this period, I have had the opportunity to witness first hand many of the changes that have been imposed upon the health care system, and specifically the mental health system, by the proliferation of managed cae. Through experiences working in many different settings, I have developed a deep personal sense both for the components of the present system that are greatly in need of change, and for the unethical and even dangerous possibilities that can arise when the changes implemented are motivated by factors other than patient welfare. At each locale, crises and conflicts that initially seemed almost unimaginable soon became everyday reality: an attending physician with over 30 years of experience in patient care forced to practically beg a managed care agent for two more days of inpatient coverage: a patient who felt "forced out of the hospital" because her coverage had expired; a fellow resident who argued loudly on the phone with a managed care reviewer who just as loudly denied his request to speak with the physician reviewer.

In so many of these instances, the conflicts were between two established and vastly different systems: that of health care, with its many years of developed treatment modalities and bureaucratic idiosyncrasies; and of the much newer system of managed care, a profit-based entity designed to curb the excesses of the former system through tight regulation and ultimately control of numerous treatment decisions that have previously been the domain of physicians.

In reviewing the growing body of literature about responses of the mental health community to the proliferation of managed care, I came across many different perspectives and opinions. Those generally in favor of the marriage of the two argue that the mental health system is greatly in need of a major change that would eliminate waste, excess, and inefficiency, while providing improved value and quality through standardized, controlled care and frequent third-party review (1-4). Those against managed care cited the dwindling amount of physician autonomy and control in important treatment decisions, resentment of standardized treatment and regulation, and worry about the loss of income (5-11).

While I firmly side with the latter group, I have begun to notice a concerning pattern of response within this literature: instead of justifying concerns based on clinical or ethical grounds, authors frequently sought to validate their objections by comparing psychiatric dilemmas to those of general medicine. Such arguments, however, did not stop at the level of mere comparison. In the October 13, 1993 edition 
of $J A M A$, Jellinek \& Nurcombe argued that, like the rest of medicine, "psychiatrists today must develop truncated treatment plans, aware that, otherwise, they force an uphill fight with managed care reviewers or that they will no longer be deemed worthy of referrals" (8). Thompson, et al., in the June, 1992 Hospital and Community Psychiatry, contend that, like the medical system, psychiatry must develop treatment plans based on "obtaining case-oriented, system-level data ... The rating systems used must be standardized and validated. ... To truly evaluate quality, measures of treatment outcome are needed" (9). In short, the message is that in order to ultimately survive in managed care psychiatry must develop a system of increasingly uniform methods of treatment.

The 'comparison complex' inherent in these arguments, a tacit need for validation by holding the practice of psychiatry up to the mirror of medicine, seems a reaction to the pressures imposed across the spectrum of mental health care by a system that forces questions readily formulated and answered in the langage of other specialities onto the very different discourses of psychiatry. "Pre-approved length of stay," for example, works much better with "average recovery time needed after non-complicated appendectomy" than it does with "housewife admitted after attempting suicide by overdose in need of inpatient stabilization, assessment, and treatment."

This leads to the heart of the conflict between psychiatry and managed care: psychiatry is not like the rest of medicine. Because of the differences which exist, attempts to 'manage' mental health within the confines of a care system designed for the medical model will ultimately prove unsuccessful. The desire to create a "homogenous, cost-efficient product" (5), may work well when trying to decide which percentage of patients with chest pain receive EKGs, or which percentage of patients with sore throats are started on antibiotics, but are not applicable to the very non-homogenous environment of the treatment of depression, or personality disorders. Most importantly, the assumptions necessary for the workings of a managed care system often imply an unconditional acceptance of a template that is ethically at odds with many of the core principles of successful psychiatric care. It is a lack of recognition and acceptance of these differences that form the template for conflict and dissatisfaction.

The issue of confidentiality is a prime example of this difference. In medical practice, issues of confidentiality arise only in the most extreme cases-whether or not to reveal a certain specific diagnosis, for example. On a daily level, questions about the right of confidentiality are less frequently encountered as treatment issues. In psychiatry, confidentiality is a basic tenant of the doctor-patient bond. As described in the Casebook of the Group for the Advancement of Psychiatry, "Nowhere is the need for confidentiality greater than in psychiatric practice. Patients in psychotherapy must be able to trust that they can speak openly about their experiences and their feelings without fear that the psychiatrist will tell others what they have said. . To breach confidentiality is to violate a moral rule with respect to a patient" (12). 
Consider, then, the complaint of a fellow resident working on one of the inpatient units:

Ms. $\mathrm{M}$ is a patient of mine-a 52 -year-old housewife who is having a severe depressive episode. She has stopped eating, stopped caring for herself, and ultimately had to be hospitalized against her will. At first, she fought it, but now she's started to come around a bit-she's eating, sleeping okay, and has started to discuss some of her feelings. But the thing I hate about this case is that each day I have to call her managed care agent, and discuss Mrs. M's intimate revelations to justify her continued hospitalization.

The demands of managed care have forced many psychiatrists to face the ethical question raised by this vignette: Is it a breach of confidentality to discuss intimate details of patient care with a third party who is not directly involved in treatment? The question in psychiatry, as in the rest of medicine, is now answered in the affirmative with such regularity as to be rendered moot. In medical and psychiatric settings across the country, the details of diagnosis and treatment are discussed between reviewers and physicians, at times in required daily phone interviews $(5,9,13)$. Issues that simply would not be pertinent if the discussion centered on cardiac medications, or post-operative care, suddenly become, by the very occurrence of these discussions, tacitly implied: confidentiality can be broken in the name of coverage.

Once this sacred trust is breached, many more questions arise to further complicate the situation: with whom will the agent share the information regarding the patient's treatment? Future employers? Credit unions? Reporters? And what is the level of confidentiality that exists within these companies, as sensitive material is routinely passed between the numerous 'external' contacts-telephone receptionists, external reviewers, etc.-and the physician reviewers (who are often not psychiatrists)?

These issues are especially pertinent in light of the 'negative stigma' often attached to those seeking psychiatric treatment, and the persistence with which this information is pursued $(14,15)$. For example, I once saw a patient who suffered from agoraphobia whose first words to me were, "I'm applying for a government job. You must assure me that what is said here is strictly confidential." "Paranoia?" I wondered with my psychiatrist's ear, but sure enough the next week I received four calls from various government agencies demanding access to my records. Internists, who had been following the same patient, however, were not contacted.

The mental health professional, once in contact with these agents, then faces an especially difficult diagnostic dilemma: he or she is caught between reluctance to assign a diagnosis which may have serious long-term implications, and the need to at times 'worsen' the diagnosis, or to, in the words of E. Haavi Morreim, "adapt his descriptions according to each payer's somewhat idiosyncratic requirements. He may even find himself engaged in 'creative writing' to emphasize those factors in which 
each particular payer is most keenly interested" (16). This process, called 'unbundling' or 'upcoding' of diagnoses, is a major argument against the reliability of chart review/outcomes research currently being funded by many major managed care companies (17). And finally, what of arguments such as that of Dr. Blackmon that the physician's bill, concomitantly a document laden with significance in many psychotherapeutic treatments, and a document required for reimbursement, "cannot be considered as a public document, and issued to an issuer ... Such consideration can undermine the very core alliance necessary for therapy to work." Questions such as these are rarely, if ever, the subject of discussion in the interactions between the worlds of health care and managed care.

A second ethical principle fundamental to successful psychiatric treatment, and at times severely compromised by managed care, is that of autonomy. Consider the following two vignettes which arose from clinical experience:

Case One: Mary was a 25-year-old female who sought treatment with an eating disorder specialist for a one-year history of what had become daily bingeing and purging, accompanied by severe weight loss and dangerous medical complications. The psychiatrist made the diagnosis of bulimia and recommended treatment with himself or another physician with experience in eating disorders. Mary called her insurance company to discsuss coverage only to learn that the specialist was not on their list of 'preferred' providers. "We will give you the name of another specialist," she was told by the insurance company, who then proceeded to refer her to a general psychiatrist with no advanced training whatsoever in eating disorders, and who had been out of residency for 26 years. When Mary called to complain, she was told, "We're sorry. He is the doctor we have available in your area." After this interaction, Mary briefly stopped treatment and her symptoms markedly worsened.

Case Two: Richard, a 43-year-old travel agent, had begun to recover from his bout of severe depression with a mix of antidepressants and weekly psychotherapy sessions. "I never realized how self-destructive my patterns of coping were," he told his therapist on the seventh session. Suddenly, however, Richard's business changed to a less-expensive insurance company, which provided no coverage whatsoever for psychotherapy. After undergoing 'consultation' with a new psychiatrist, who reaffirmed the diagnosis of depression, Richard was switched to a less-expensive antidepressant and following with monthly 15-minute follow-up sessions for medications only. Richard's numerous requests for psychotherapy were denied by the company, who repeatedly claimed he was getting "the best treatment available." His depression worsened considerably and two months later he was hospitalized.

Is it a patient's right to seek within reasonable limits the most effective treatment available? Do curbs on this right decrease the potential for positive outcome? Managed care companies have claimed that a limitation of choice of 
provider is done not to find the least expensive doctor or nurse, but to find "the provider who is the most appropriate" (1) for their patient population. As Hall points out, however, the lists of "qualified providers" are influenced almost wholly by profit motives: "Profit in these systems is maximized by a bureaucracy that ... encourages the provision of treatment by the least-costly professional" $(1,18)$. In a medical setting, limitations of this autonomy may or may not affect the outcome of care: patients frequently ask to remain with 'their' doctor because, "He is nice,' or, "She has known me since I was born," but rarely because, "He believes in treating otitis media with antibiotics, while Dr. Jones uses herbal remedies." Within the confines of the medical establishment, standardized treatments for most common ailments exist, regardless of the doctor-patient bond.

However, in psychiatry the doctor-patient relationship often is the treatment, or a very large component of it, with all but the most severely ill patients. Patients must often choose, by themselves or with assistance, between a great variety of possible treatment philosophies, from the most dynamic to the most biological. These decisions are highly individual, and often require a period of trial-and-error before the right 'match' is attained. The woman in case number one, for example, eventually returned to the initial specialist, at great personal expense, because, "It just felt like he understood me." Indeed, even after the biological revolution in psychiatry, studies continue to show that one of the highest predictors of positive outcome for many outpatient diagnoses is not the choice of medication alone, but patient satisfaction with the therapist. In a July, 1994, study, for example, Conte and Buckley once again demonstrated that patients who saw their therapists as respectful, understanding, competent, and giving of good advice were much more likely to show recovery (19).

This choice is curtailed by the common managed care practice of choosing providers, and, by extension, philosophies of treatment (antidepressants over psychotherapy for depression, for example) based solely on finance, an irrespective of efficacy. Is this the provision of responsible coverage? Does this a priori limitation of autonomy portend a later escalation of symptoms, and the need for more involved care, as was the case in the second vignette? Such questions have been addressed in other 'managed' systems, such as the Canadian "brokerage" model (20), but are not even brought up in the profit-driven, private system of our present and our future.

The loss of autonomy, also extends to mental health care providers, who have found some fundamental decisions of psychiatric treatment taken out of their hands. These include decisions on billing (7), on the determination of the duration of treatment (1), and decisions of hospital discharge (6). While each of these are issues faced by physicians across the spectrum of medicine, they carry special, different connotations within the world of mental health, and should be addressed accordingly.

If such sensitivity is not incorporated into the system, the very real possibility exists that the provision of care offered by the mental health community will actually worsen, and will also become more costly. "Our patients have not changed, but the level of care we provide them has diminished" in the face of "a rapid increase in medical costs" $(5,21)$. This insensitivity is seen with the imposition of structures that may be effective in other parts of the system, but which will lead to recidivism, 
noncompliance, exacerbation, and ultimately failure in the field of mental health. These include the weakening of the doctor-patient bond; and the practice of limiting treatment for patients who practice 'unhealthy' behaviors including smoking, noncompliance with medications, and missed appointments (22). This may have been effective in dealing with those at risk for heart disease, but could hardly be seen as effective in treatment of a patient with schizophrenia who is too paranoid to pick up his prescription; or a patient with OCD whose obsessions render her unable to leave home; or a patient with borderline personality disorder who would view termination of benefits as a sign of rejection, and a reason to worsen acting out behaviors.

One of the issues I find the most disturbing in this time of drastic change is a feeling that I have entered a system where changes have forced otherwise wellintentioned care givers to act unethically: doctors who are caught as 'double agents,' concomitantly bonded to their patients who are in need of care, and insurance companies who seek to restrict it; case managers who learn to 'creatively' describe a patient's condition to managed care agents in order to procure vital treatments; and nurses who are forced to cut back on inpatient services because 'the patients just aren't in the hospital long enough." I realize that there is a need for change-signs of dwindling resources and increasing costs are ubiquitous, especially in mental health where expenses have continued to rise at a rate greater than those in the rest of health care $(13,21)$.

Of far greater concern is the possibility that equally pressing ethical issues of meaningful treatment are being swept under the table in this frenzy of competition and cost cutting. I fear that if important treatment decisions continue to be made by logarithm and computer, rather than on an individual basis, taking into account the "cheapest" and "quickest" instead of the "most appropriate," although sometimes more involved; and, if patients' basic rights such as autonomy and confidentiality, which guarantee their active involvement in the process of treatment, continue to be taken away-it will portend a career of frustration for myself and others in my position and, even worse, heightened suffering and pain for those already burdened with mental illnesses.

\section{REFERENCES}

1. Olsen DP: Ethical considerations of managed care in mental health treatment. J Psychosocial Nurs and Mental Health Services 1994; 32(3):25-28.

2. Patterson DY: Managed care: an approach to rational psychiatric treatment. Hospital and Community Psychiatry 1990; 41:1092-1095.

3. Rupp A: The effect of hospital payment method on the pattern and cost of mental health care. Hospital and Community Psychiatry 1984; 35:456-459.

4. Walker J, Aquilina D: Managing mental health cost. Health Span 1986; 3:11-15.

5. Hall RC: Social and legal implications of managed care in psychiatry. Psychosomatics 1994; 35(2):150-158.

6. Lewin R, Scharfstein SS: Managed care and the discharge dilemma. Psychiatry 1990; 53:116-126.

7. Blackmon WD: Are pscyhoanalysts' billing practices ethical? Am J Psych 1993; 47:613-620. 
8. Jellinek MS, Nurcombe B: Two wrongs don't make a right: managed care mental health and the market place. JAMA 1993; 270(14):1737-1739.

9. Thompson JW, Burns BJ, Goldman HH, Smith J: Initial level of care and clinical status in a managed mental health program. Hospital and Community Psychiatry 1992; 43(6):599_ 603.

10. Applebaum PS: Modifying the impact of managed care. Hospital and Community Psychiatry $1993 ; 44(6): 525-527$.

11. Sabin JE: Clinical skills from the 1990s: six lessions from HMO practice. Hospital and Community Psychiatry 1991; 42(6):605-608.

12. Group for the Advancement of Psychiatry. A Casebook in Psychiatric Ethics. New York, 1990.

13. Dickey B, Azeni H: Impact of managed care on mental health services. Health Aff 1992; 11:197-204.

14. Barker P, Baldwin S, eds: Ethical Issues in Mental Health. London, 1991.

15. Middleton CL: Rights and respect: legal and ethical issues challenge today's mental health care professionals. Health Progress 1991; 38-44.

16. Morreim EH: The new economics of medicine: special challenges for psychiatry. J Med and Philosophy 1990; 15:97-119.

17. New frontiers in research: mining patient records. New York Times August 9, 1994.

18. Relman AJ: What market values are doing to medicine. Atlantic Monthly 1992; 99-106.

19. Conte MR, Buckley P: Relations between satisfaction with therapist and psychotherapy outcome. J Psychther Pract Res 1994.

20. Brandon D, Towe N: Free to Choose: An Introduction to Service Brokerage. London. 1989.

21. National Association of Private Psychiatric Hospitals. NAPPH Annual Survey. Washington, 1990.

22. Terry P: Health incentive systems and risk rating. HMO Practice 1993; 7(1):15-19.

23. Braynt M: Are rising mental health costs driving you crazy? Business and Health. 1991; $36-43$. 